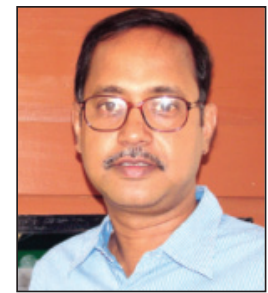

JOURNAL OF MINES, METALS \& FUELS www.jmmf.info

f Linkedin

Jayanta Bhattacharya

Hony. Chief Editor

Minnovation $^{\mathrm{TM}}$

\title{
Underground communication is keeping pace with surface communication
}

Virtually every application in an underground mine can benefit from the addition of reliable and real-time video and data monitoring. All underground equipment continuously generate real-time data: load, distance, time, operating current, power, vibration, noise, dust, temperature, and many others. Persistent research has gone into capturing and utilizing the data and it is now delivering results. Recent advances in wireless communications and platforms to extract the data from these machines and transmit it to the surface, where it can be analysed for fault logging, productivity, and perhaps ultimately, for remote operations, have been making it possible. When an expensive machine asset breaks down or is not running optimally, the opportunity cost is hard to measure without reliable data. Underground broadband powerline modem solutions have proven to be extremely reliable for longwall systems in underground coal mines around Australia and abroad. That success has since been transferred over to continuous miners and more recently, shuttle cars.

A case analysis is showing that a continuous miner application includes: (a) Clear data communication to the CM, (b) Data link retained when CM turned a corner, (c) Successful data transfer across existing trailing cable lengths up to $500 \mathrm{~m}$, (d) Connectivity between network-enabled gear such as VOIP phones, protection relays, and cameras, (e) Protection from mining environment, (f) Use of portable equipment without wires through wifi hotspots, (g) Consistent high bandwidth, (h) Coverage in areas where it is needed, (h) Simple installation and (i) Reliable communication with the surface. More recently, a BPLM solution was tested on a shuttle car at Swanson Industries in New South Wales. Results of the test showed: 1. Data could be transferred from a moving machine, 2. Data rate was $20 \mathrm{Mbps}$, 3. Distance tested 357 metres.

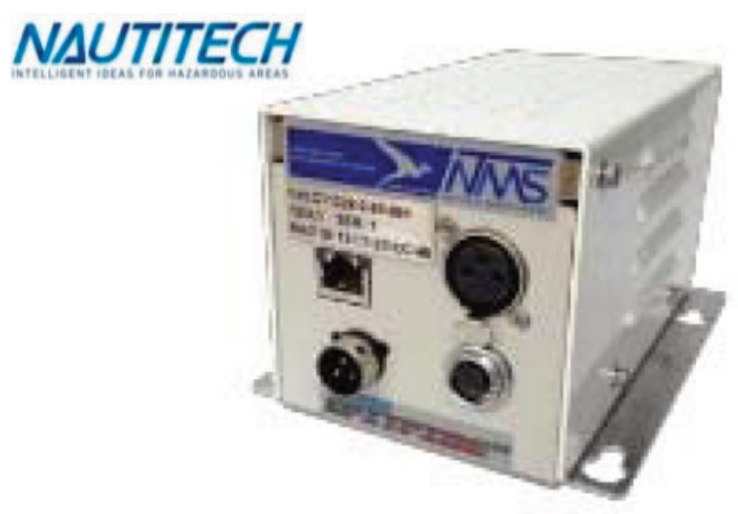

Case study

Main components: Powerline MOdem KIT

- Spitfire BPLM

- Remote display assembly

- Capacitive couplers

- Power cable

- Power-line bus cable

- Long range Spitfire BPLM (optional, for DCB if no fibre exists between transformer and DCB)

\section{Conclusion}

- The Spitfire BPLM wifi solution installed at Ensham and the 1 st system in the field for 12 weeks

- Physical layer data rate consistently around $50 \mathrm{Mbps}$ with no drop outs

- Subsequently, a second system has been installed into another CM

- Ensham looking to extend the use of the BPLM wifi system into their other applications. 